\title{
Tapping the Power of Music in Sport and Exercise
}

\author{
Costas I. Karageorghis \\ School of Sport \& Education \\ Brunel University, London \\ costas.karageorghis@brunel.ac.uk \\ http://www.brunel.ac.uk/sse/sport-sciences/people/dr-costas-karageorghis
}

\section{KEYNOTE ABSTRACT}

Music is now almost omnipresent in sport and exercise environments. It is recognised by researchers and practitioners alike as having the potential to produce significant benefits for physical performance as well as the psychological state of performers if used judiciously. At the 2012 London Olympiad, many of the world's finest athletes will tap the power of music as part-and-parcel of their pre-event preparation. This interactive presentation will provide a review and synthesis of the theory, research findings and applications of music in the domain of sport and exercise. The presenter will draw upon his published and applied work from the last 20 years to illustrate novel music applications and provide suggestions for future advances in this domain. Also a new theoretical model will be advanced, which emphasises the principal benefits of music: improved mood, pre-event activation or sedation, reduced perceptions of exertion, enhanced work output and duration, improved skill acquisition, incidence of flow states, and dissociation from feelings of pain and fatigue. The antecedents of these benefits are thought to comprise of factors relating to both the structure of music and the way in which it is interpreted. Using findings from recent studies, applied examples will be expounded with the aim of empowering delegates to tap the ergogenic and psychological effects of music for themselves.

\section{BIOGRAPHY}

Dr Costas Karageorghis is deputy head (research) of the School of Sport and Education at Brunel University, London. He has spent the last 20 years conducting research into the psychological and ergogenic effects of music in the domain of exercise and sport. Costas has written in excess of 150 scholarly articles and worked as a consultant psychologist with many national governing bodies of sport in the UK and with multi-national companies including Nike, Sony, Red Bull and IMG. His research is cited more than 100,000 times on Google and several TV documentaries have been made about his work, including one by the Discovery Channel. Costas's latest book is Inside Sport Psychology (Human Kinetics Publishers, 2011): http://www.humankinetics.com/products/allproducts/the-inside-sport-psychology. 